\title{
Indicadores Industriais dos Estados do Sudeste Brasileiro: Uma Análise sobre Desindustrialização a partir de Modelos ARDL*
}

\author{
Michele Polline Veríssimo \\ Instituto de Economia e Relacionais Internacionais (IERI) \\ Universidade Federal de Uberlândia (UFU)
}

\begin{abstract}
Resumo: Este artigo investiga a hipótese de desindustrialização nos estados da região Sudeste brasileira a partir da análise de indicadores de produção, emprego e exportações de bens manufaturados, conforme os principais conceitos do problema apontados pela literatura econômica. Além disso, avalia as possíveis causas do processo por meio da estimação de modelos Auto Regressivos de Defasagens Distribuídas (ARDL) que relacionam os efeitos da taxa de câmbio real, dos preços das commodities, do grau de abertura comercial e da taxa de juros básica da economia sobre os indicadores industriais analisados. Os dados assinalam perda de participação da indústria de transformação na produção, no emprego e nas exportações nos estados do Sudeste, sobretudo em São Paulo, indicando desindustrialização. Contudo, as evidências econométricas sugerem que a apreciação cambial e os altos preços das commodities não se mostraram relevantes para explicar tais resultados. A abertura comercial foi prejudicial especialmente ao emprego, e a taxa de juros exerceu efeitos negativos sobre os indicadores industriais em todos os estados da região.
\end{abstract}

Palavras-chave: Indicadores Industriais; Desindustrialização; Estados; Região Sudeste.

Abstract: This paper investigates the deindustrialization hypothesis in the Brazilian Southeast states, based on the analysis of production, employment and exports indicators for manufactured goods, according to the main concepts of the problem pointed out by the economic literature. In addition, it analyses the possible causes of the process by estimating Auto Regressive Distributed Lag (ARDL) models that relate the effects of the real exchange rate, commodity prices, trade openness degree and the interest rate on the industrial indicators selected. The data indicate a loss of participation of the manufacturing industry in the production, employment and exports in the Southeast states, especially in São Paulo, indicating deindustrialization. However, the econometric evidence suggest that exchange appreciation and high commodity prices were not relevant to explain such results. Trade liberalization has been especially damaging to employment, and the interest rate had negative effects on industrial indicators in all Southeast states.

Key-words: Industry Indicators; Deindustrialization; States; Southeast Region.

Área 1 - Indústria e competitividade

1.4 Padrões de especialização produtiva e desenvolvimento

JEL: L16; L60; O14

\footnotetext{
* A autora agradece à Fundação de Amparo à Pesquisa de Minas Gerais (FAPEMIG) pelo apoio financeiro à pesquisa.
} 


\section{Introdução}

A indústria de transformação brasileira, ao longo dos anos 2000, tem perdido desempenho na geração de produto, emprego e exportações, em um contexto de preços e demanda externa favoráveis aos produtos primários. Esta conjuntura foi acompanhada por movimentos cambiais, em que, durante boa parte do período, a taxa de câmbio real apreciada beneficiou os setores produtores de commodities, os quais detêm vantagens comparativas no comércio internacional, sendo que, de 2012 em diante, a depreciação cambial ocorrida não surtiu os estímulos positivos esperados em termos da inserção internacional dos produtos manufaturados. Além disso, a prática de taxas de juros elevadas e o cenário de incerteza em meio ao ambiente de crise externa (norte-americana) e de fragilidade institucional interna (Operação Lava Jato) vivenciadas ao longo do período contribuíram para desestimular os investimentos na esfera produtiva, com efeitos perversos sobre os resultados industriais no país.

Tendo em vista os argumentos da literatura econômica kaldoriana de que os produtos manufaturados, em tese, são caracterizados por maiores economias de escala, maiores coeficientes de elasticidade-renda, além de fortes efeitos de aprendizado e de encadeamento produtivo e tecnológico com os outros setores da economia (agropecuária e serviços), a perda de desempenho da atividade industrial pode contribuir para a obtenção de taxas menores de crescimento econômico no longo prazo. Tal preocupação tem motivado um debate sobre a ocorrência e as possíveis causas de um processo de desindustrialização no Brasil.

Deste modo, torna-se relevante verificar o desempenho da indústria de transformação no contexto regional, dado que as diversas regiões do país possuem características industriais particulares que são afetadas de modo e intensidade distintas pelos condicionantes econômicos. No caso dos estados da região Sudeste, a principal região industrial brasileira, os perfis industriais são bastante distintos. O estado de Minas Gerais se destaca nos setores de minerais ferrosos, siderúrgico, café e automotivo. O Rio de Janeiro é caracterizado por uma estrutura produtiva e exportadora baseada nas atividades petrolíferas. O Espírito Santo também possui uma indústria fundamentada em bens primários (minério de ferro, aço, celulose, e, recentemente, petróleo e gás), enquanto São Paulo responde pelo maior volume da produção e da exportação de produtos manufaturados de alta e médiaalta tecnologia do país.

Cabe destacar que, embora a região Sudeste concentre mais da metade da produção industrial brasileira, é possível notar uma perda de participação da sua indústria (transformação e extrativa) no valor adicionado (VA) ao Produto Interno Bruto (PIB) do país, passando de 59,7\% em 2002 para $55,0 \%$ em 2015, segundo dados do IBGE (2018). Considerando o peso da região na determinação dos resultados econômicos nacionais (produto, emprego e exportações), torna-se relevante investigar a hipótese de desindustrialização na região.

Este artigo, portanto, analisa indicadores tradicionais da indústria de transformação dos quatro estados que compõem a região Sudeste do Brasil - São Paulo, Minas Gerais, Rio de Janeiro e Espírito Santo - com o objetivo de obter evidências sinalizadoras (ou não) de desindustrialização em termos da perda de desempenho da produção, do emprego e das exportações de bens manufaturados naqueles estados e suas possíveis causas.

Para isso, será utilizada a metodologia de cointegração pela estimação de modelos Auto Regressivos de Defasagens Distribuídas (ARDL), na tentativa de obter evidências sobre os efeitos de algumas variáveis listadas pela literatura econômica como relevantes para explicar um possível processo de desindustrialização em curso, quais sejam, a taxa de câmbio real, os preços dos produtos primários (commodities), o grau de abertura comercial e a taxa de juros básica da economia (Selic).

Este artigo apresenta duas contribuições principais. A primeira se relaciona à investigação da hipótese de desindustrialização em termos regionais. A literatura tem avançado na discussão das especificidades da estrutura produtiva em estudos de casos para as regiões (estados) do Brasil, mas ainda há bastante espaço para o tratamento empírico do tema. Assim, a segunda contribuição do artigo 
consiste no método utilizado, visto que a maior parte dos trabalhos são baseados na descrição de indicadores industriais tradicionais, não aprofundando na investigação quantitativa sobre as possíveis causas de curto e longo prazos do problema.

O artigo está organizado em seis seções, incluindo esta introdução. A seção 2 sistematiza a discussão sobre desindustrialização nos estados da região Sudeste brasileira. A seção 3 apresenta os conceitos relevantes de desindustrialização analisados e os indicadores correspondentes para os referidos estados. A seção 4 expõe a metodologia utilizada. A seção 5 discute os resultados obtidos. A última seção elabora as considerações finais.

\section{Debate sobre Desindustrialização na Região Sudeste}

A literatura sobre desindustrialização no âmbito regional é basicamente pautada pela investigação do perfil industrial das regiões (estados) a fim de obter evidências sobre a perda de importância da indústria de transformação no valor adicionado (VA), no emprego e nas exportações. Esta seção do artigo sistematiza os principais resultados encontrados em trabalhos que analisam o caso da região Sudeste brasileira, com dados para os anos 2000.

Por exemplo, em estudos regionais, os trabalhos de Monteiro e Lima (2017) e Botelho et al. (2014) verificam perda de participação da atividade industrial no PIB e no emprego, especialmente nos estados das regiões Sudeste e Nordeste, além de redução de participação dos produtos industriais nas exportações e nas importações. Os autores também constatam desconcentração das indústrias tradicionais do Sudeste para as demais regiões do país, com especialização da região nos segmentos com maior conteúdo tecnológico.

Avaliando dados de pessoal ocupado no período 1990-2009, Cruz e Santos (2011) destacam que as maiores perdas de empregos industriais ocorreram no Sudeste, concentradas nas indústrias tradicionais. Ambrozio (2007) também constata que a indústria de transformação da região Sudeste, especialmente em São Paulo e no Rio de Janeiro, perdeu participação aguda no emprego, ao passo que as demais regiões elevaram a participação, com destaque para o Sul, pelo deslocamento de empresas para Paraná e Santa Catarina.

Manhães e Rosendo (2016) analisam o indicador de Vetor de Densidade Industrial (VDI) dos estados da região Sudeste de 2000 a 2010, o qual considera a participação das empresas, a produção industrial, as exportações e a diversidade produtiva da indústria. Os resultados revelam que os estados do Rio de Janeiro e de São Paulo tiveram significativa queda em seus respectivos VDI, indicando que ambos têm perdido competitividade e passam por uma desindustrialização que tem afetado negativamente suas economias.

Pereira e Cario (2016), por meio do Índice de Desindustrialização Relativa Regional (DRR) para São Paulo, Rio de Janeiro e Minas Gerais, no período de 1996 a 2013, constatam a existência de desindustrialização para a indústria de transformação como um todo. Porém, os estados tiveram comportamentos diferenciados, visto que a indústria paulista apresentou desindustrialização relativa durante todo o período analisado, enquanto Minas Gerais e Rio de Janeiro apresentaram melhor performance principalmente a partir de 2007, com mudança estrutural dos setores de baixa para média alta tecnologia.

A literatura também aborda a hipótese de desindustrialização em estudos para os estados individualizados. Por exemplo, sobre o estado de São Paulo, Ferreira (2003) observa perda de participação do emprego industrial relativamente ao setor de serviços atrelada ao aumento do setor informal e à precarização do trabalho. Apesar das políticas neoliberais de abertura do mercado a partir de 1990, o autor não confirma a ocorrência de desindustrialização no estado, mas um movimento de desconcentração industrial da capital para o interior ou outros estados.

Rezende e Santos (2007) apontam que as medidas do Plano Real (abertura comercial, juros elevados e apreciação cambial) promoveram a reestruturação do parque produtivo aos padrões de competitividade internacional, aumentando o desemprego. Neste contexto, as fábricas do ABC 
paulista migraram para outras regiões do país e do próprio estado, na busca de menores salários e incentivos fiscais, sendo que as que restaram ampliaram investimentos em tecnologia, elevando a produtividade e aumentando o desemprego industrial local.

Já Costa et al. (2013) ressaltam que o contexto do Plano Real contribuiu para a deterioração da indústria de transformação brasileira no período 1989-2010, com menor agregação de valor nacional à produção, substituição de demanda por produtos importados e perda de participação nas exportações. O estado de São Paulo, por concentrar o principal parque industrial do país e boa parte dos segmentos mais complexos, foi mais afetado do que o restante da economia nacional, com desaceleração e regressão na estrutura industrial.

Silva e Alves (2010) também assinalam que as políticas implementadas com o Plano Real levaram à queda da participação da indústria de transformação no PIB, mas com efeitos distintos nos vários estados brasileiros. Nestes termos, o estado de Minas Gerais aumentou a participação da indústria de transformação no total do país, especialmente nas atividades ligadas à produção de minério de ferro, siderurgia e fabricação de automóveis, camionetas e utilitários no período 19962006.

Com base em dados do período 1960-2010, Almeida e Souza (2014) apontam que a indústria mineira ampliou participação no VTI nacional, mediante queda do peso dos estados do Rio de Janeiro e de São Paulo. Também observam diversificação produtiva, com avanço dos setores de extração de minerais, metalurgia, produtos alimentares, material de transporte, química e mecânica. Todavia, na produção física, desde a reposição em volume ocorrida em 2010 em resposta à crise econômica, a indústria mineira permanece estagnada.

Por outro lado, Veríssimo e Araújo (2016) destacam que a indústria de transformação mineira perdeu peso relativo frente à atividade extrativa no PIB do estado, e apresentou deterioração em seu conteúdo tecnológico. Os autores obtêm impacto favorável de uma taxa de câmbio real depreciada sobre a indústria de transformação, sugerindo que, num quadro de apreciação cambial, o estado pode enfrentar desindustrialização no longo prazo. Ainda, as taxas de juros elevadas e a abertura comercial foram prejudiciais à atividade de transformação, mas tais efeitos não foram observados para a indústria extrativa.

Cruz (2012) argumenta que o Rio de Janeiro passa por um ciclo de industrialização e aumento da infraestrutura vinculado ao perfil exportador de commodities, baseado na exploração de recursos naturais e na produção de alimentos e bens industriais semi-acabados, contando com o avanço das indústrias siderúrgica, naval, automotiva e petroquímica. $\mathrm{O}$ autor considera que a indústria fluminense lida com uma inflexão positiva, com o surgimento de novos setores e a expansão de segmentos industriais para o interior do estado.

Em contraponto, Rosendo e Britto (2011) argumentam que a forte expansão da indústria fluminense foi liderada pelos setores de refino e de exploração e produção de petróleo e gás. Assim, a indústria de transformação perdeu peso no VTI estadual entre 1996 e 2005, ao passo em que aumentou a contribuição da indústria extrativa, com aumento da concentração setorial, baixa produtividade de setores tradicionais e redução do número de empresas. Em adição, Sobral (2013) assinala que o dinamismo da indústria extrativa mineral contrasta com o quadro de semi-estagnação da indústria de transformação, revelando uma condição dependente do aproveitamento de recursos minerais e indícios de desindustrialização relativa.

Caçador e Grassi (2009) argumentam que a especialização da economia espírito-santense em commodities foi fundamental para a obtenção de altas taxas de crescimento. Contudo, o estado ainda é periférico na geração e incorporação de conhecimento ao processo produtivo. A diversificação produtiva da economia deve ser estimulada, pois problemas potenciais com a produção de commodities podem prejudicar o crescimento no longo prazo.

Villaschi Filho e Leal (2012) apontam que o Espírito Santo ampliou a participação das exportações de produtos básicos e reduziu a de semimanufaturados e manufaturados na pauta comercial brasileira entre 2000 e 2011. Ainda, a indústria extrativa mineral ganhou relevância em 
detrimento da indústria de transformação no VA do Brasil. Tais evidências indicam que o estado colaborou para a entrada de divisas no país oriundas da venda de produtos primários, contribuindo para a apreciação artificial do câmbio indicada como "Doença Holandesa".

Caçador (2015) investiga a hipótese de desindustrialização no Espírito Santo pela estimação de um modelo que avalia a relação em $U$ invertido entre a participação da indústria no Valor Adicionado Total (VAT) e a renda per capita. Este autor não encontra evidência de que a economia capixaba esteja sofrendo desindustrialização. Tendo em vista que a estrutura industrial capixaba é fortemente concentrada em commodities, são obtidas evidências de efeitos positivos dos preços daqueles bens sobre a participação da indústria no VAT local.

Em síntese, a literatura que analisa as características da estrutura produtiva dos estados da região Sudeste aponta que a região concentra boa parte da atividade industrial do país, mas a dinâmica entre os estados é distinta. O estado de São Paulo ainda concentra a produção de bens industriais de maior intensidade tecnológica, embora tenha sofrido alguma desconcentração para outros estados do país. De outro lado, os demais estados do Sudeste ampliaram o peso da indústria baseada em recursos naturais (especialmente minerais e petróleo). Sendo assim, torna-se relevante investigar se esse resultado é sinalizador de um processo de desindustrialização, em que a indústria de transformação perde importância na geração de produto, emprego e exportações. A próxima seção do artigo apresenta os conceitos e os indicadores que fornecem uma perspectiva da evolução da indústria de transformação dos estados da região Sudeste durante os anos 2000.

\section{Medidas de Desindustrialização e Indicadores Industriais dos Estados da Região Sudeste}

A literatura econômica trabalha com vários conceitos e indicadores para o termo “desindustrialização". No conceito original de Rowthorn e Wells (1987) e Rowthorn e Ramaswany (1999), a desindustrialização é tratada como um processo de redução persistente da participação da indústria no emprego total. Neste caso, a desindustrialização é decorrente do aumento da produtividade da mão de obra na indústria, que passa a ser absorvida pelo setor de serviços. Ainda, diferenças nas elasticidades-renda setoriais levam ao aumento da demanda por serviços com o aumento da renda ao longo do tempo, o que resulta em contratação de mais trabalhadores pelo setor, aumentando sua participação no emprego e reduzindo o peso dos demais setores. Nestes termos, a desindustrialização não é necessariamente indesejável, desde que seja resultado de um processo "natural" atrelado ao desenvolvimento econômico, o que estabelece um formato de "U invertido" entre grau de industrialização e renda per capita. ${ }^{1}$

No entanto, há críticas quanto à mensuração da desindustrialização pela análise do emprego, visto que a demanda por produtos manufaturados pode ser afetada por mudança nas exportações, pela redução na taxa de investimento e ainda pela terceirização de atividades manufatureiras, que passam a ser classificadas como de serviços. Esses fatores contribuem para a redução da participação industrial no emprego total, mas não necessariamente no produto.

De tal modo, Tregenna (2009) expande o conceito de desindustrialização, definindo-o como sendo a situação na qual a indústria perde participação tanto no emprego como no produto (PIB). Segundo a autora, pelos pressupostos kaldorianos, a indústria tem propriedades importantes para o crescimento, tais como maiores efeitos de encadeamento para frente e para trás com os demais setores, economias de escala e efeitos de aprendizagem. Assim, mesmo que o emprego industrial reduza, se a produção industrial cresce, a economia é beneficiada pela maior demanda por insumos com encadeamentos para trás ou por reduções de custos nos setores com encadeamentos para frente. Ademais, a indústria pode aumentar sua participação no PIB, mesmo com declínio de participação

\footnotetext{
${ }^{1}$ Alguns países em desenvolvimento perderam participação da indústria sem que a economia tenha alcançado níveis de renda per capita semelhantes aos dos países desenvolvidos. Tal processo é denominado desindustrialização "precoce" (CARVALHO; KUPFER, 2007).
} 
no emprego, devido a mudanças tecnológicas e/ou na composição dos setores industriais que podem resultar em menor número de empregados.

O conceito de desindustrialização ampliado de Tregenna (2009) é defendido por Oreiro e Feijó (2010), os quais também adicionam que o fato de haver expansão da produção industrial não indica que inexiste desindustrialização. Pelo contrário, argumenta-se que o processo é compatível com um crescimento físico da produção industrial. Nestes termos, a desindustrializando ocorre quando há redução da importância da indústria como fonte de geração de emprego e de valor adicionado. Os autores ressaltam que a diminuição da participação da indústria pode decorrer do aumento da participação de produtos de maior conteúdo tecnológico ou valor adicionado nas exportações, com efeitos benéficos sobre a economia. Nesse caso, a desindustrialização é vista como "positiva". Já se a desindustrialização vier acompanhada pela reversão da pauta exportadora na direção de commodities, produtos primários ou manufaturas com baixo valor adicionado e/ou conteúdo tecnológico, é classificada como "negativa", pois resulta de uma falha de mercado na qual a existência e/ou a descoberta de recursos naturais gera apreciação cambial, com externalidades negativas sobre a produção de bens manufaturados.

Em linha, a desindustrialização pode ser vista como consequência de um problema de "Doença Holandesa", em que a abundância de recursos naturais que proporcionam vantagens comparativas ao país e/ou o aumento dos preços internacionais das commodities promovem a entrada de divisas, ocasionando apreciação cambial acima da taxa de câmbio de equilíbrio industrial, a qual é necessária para garantir rentabilidade adequada ao setor produtor de bens comercializáveis que utilizam tecnologia sofisticada (BRESSER-PEREIRA, 2007, OREIRO; FEIJÓ, 2010). Esse processo contribui para a especialização da economia na produção de bens primários, prejudicando o desempenho da indústria de transformação e inibindo o crescimento econômico no longo prazo. Este tipo de desindustrialização é percebido diante de um aumento do déficit comercial da indústria pela perda de participação dos bens manufaturados nas exportações, ou pela substituição dos produtos nacionais pelos importados, desestimulando o consumo de produção interna.

Ainda, autores, como Palma (2005) e Cano (2012), apontam que a desindustrialização pode surgir por influência das políticas econômicas de estabilização praticadas a partir da década de 1990, como no caso das economias latino-americanas, em que a sobrevalorização cambial em conjunto com medidas de abertura comercial e financeira e a prática de taxas de juros elevadas resultaram em perda de competitividade da indústria nacional frente ao mercado externo. Com o fechamento de empresas nesse contexto desfavorável, a indústria perdeu participação no PIB e ampliou o hiato do emprego. Portanto, tais políticas teriam contribuído para a especialização da estrutura produtiva em bens primários nos quais os países teriam vantagens comparativas ricardianas.

Diante dessa discussão, cabe analisar os indicadores do desempenho da indústria de transformação dos estados da região Sudeste brasileira, quais sejam a participação no emprego (conceito de Rowthorn e Ramaswamy, 1999), no produto (Tregenna, 2009) e nas exportações (Bresser-Pereira, 2007) a fim de obter evidências de desindustrialização ao longo dos anos 2000.

O Gráfico 1 apresenta a participação anual da indústria de transformação no emprego (pessoal ocupado em 31/12) dos estados da região Sudeste no período 2000-2016. Observa-se que a indústria de transformação perdeu participação no emprego total em todos os estados. Destaca-se o caso de São Paulo, cuja atividade foi responsável, em média, por 21,39\% do emprego no período, e sofreu a maior queda de participação (-5,04 p.p.), passando de 22,97\% em 2000 para 17,93\% em 2016. Em Minas Gerais, a indústria de transformação colaborou com 17,16\%, em média, do emprego no estado, reduzindo participação em 1,71 p.p.. No estado do Espírito Santo, cuja participação média foi de $13,71 \%$, a redução do emprego industrial foi de 1,88 p.p., resultado próximo ao do Rio de Janeiro, com queda de 1,86 p.p., embora, neste estado, a indústria de transformação tenha sido a que menos colaborou com a geração de emprego (média de 10,35\%). 
Gráfico 1 - Participação da indústria de transformação no emprego total dos estados da região Sudeste, 2000 a 2016 (em \%)

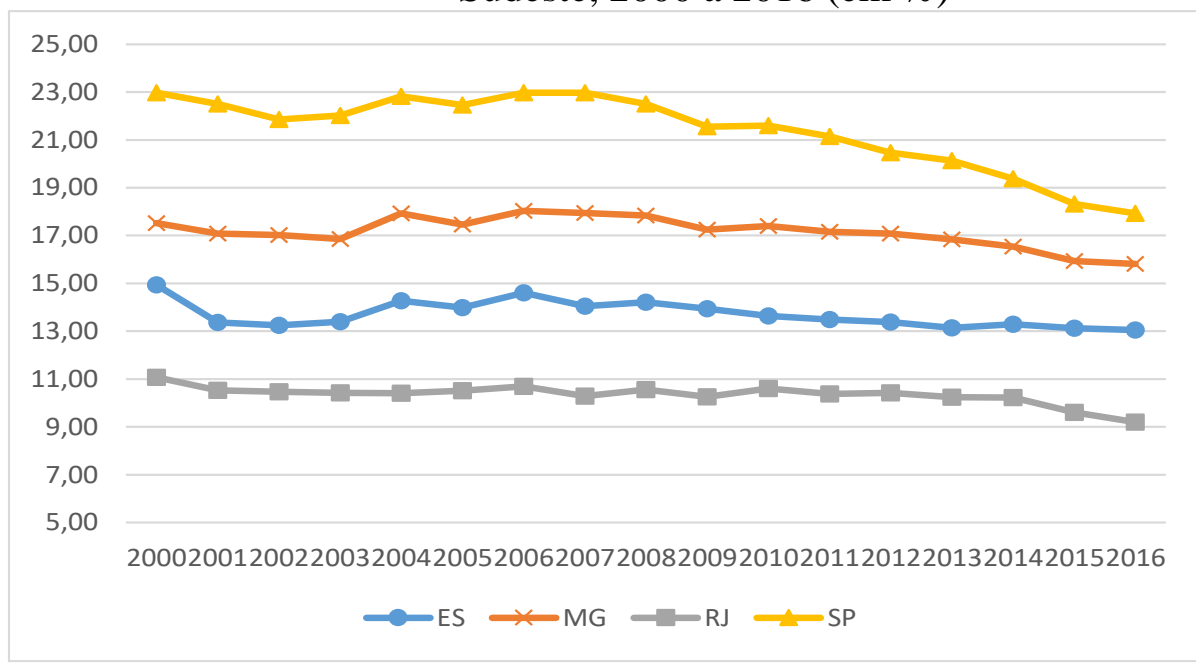

Fonte: MTE-RAIS

Tendo em vista que o dado de emprego pode sofrer a influência dos ganhos de produtividade da força de trabalho industrial, o Gráfico 2 ilustra a participação do valor adicionado pela indústria de transformação no PIB de cada estado no período 2002-2015. ${ }^{2}$

Gráfico 2 - Participação da indústria de transformação no PIB dos estados da região Sudeste, 2002 a $2015(\mathrm{em} \%)$

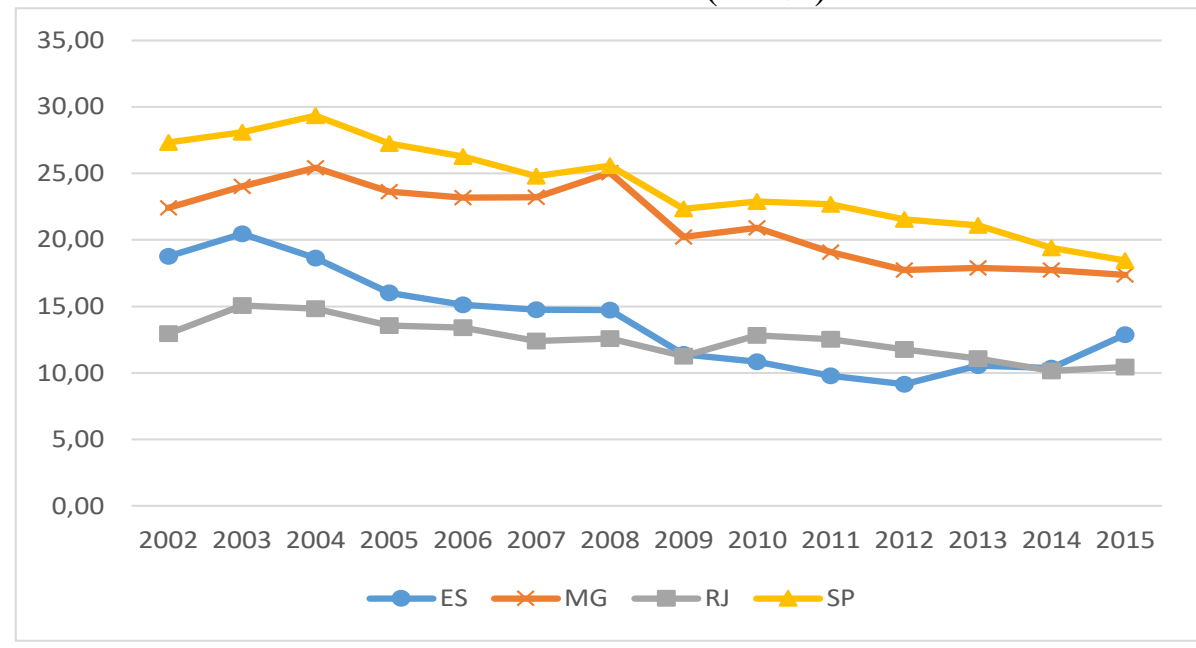

Fonte: IBGE - PIA Empresa

Novamente, percebe-se que a indústria de transformação de todos os estados passou a colaborar menos com a geração de produto nos estados da região Sudeste no período analisado. O estado de São Paulo, que possui a maior participação do valor adicionado pela indústria de transformação no PIB, em média, 24,08\%, foi também o que deteve maior queda no indicador (-8,9 p.p.), passando de 27,33\% em 2002 para 18,44\% em 2015. A indústria de transformação em Minas Gerais e Espírito Santo, cujas participações médias no PIB foram de 21,28\% e de 13,82\%, respectivamente, perderam peso no produto de 5,03 p.p. e 5,89 p.p., na mesma ordem. No Rio de Janeiro, a contribuição industrial ao PIB foi relativamente menor (média de 12,5\%), e a queda correspondente no indicador foi de 2,5 p.p.

\footnotetext{
${ }^{2}$ Devido à mudança de metodologia no cálculo do PIB pelo IBGE em 2010, optou-se por iniciar a análise no ano de 2002 para manter a coerência dos dados, sendo que a disponibilidade dos mesmos vai até o ano de 2015.
} 
Embora, de acordo com Oreiro e Feijó (2010), a desindustrialização possa ocorrer mesmo com o crescimento da produção industrial, em complemento à análise dos efeitos da indústria de transformação sobre o produto, o Gráfico 3 descreve o desempenho da produção física (volume) do setor no período 2002-2017. Verifica-se que, até 2008, a indústria de transformação apresentou crescimento real em todos os estados da região Sudeste, mesmo com o contexto de apreciação cambial, abertura econômica e preços favoráveis aos produtos primários observados até então. Contudo, a ocorrência da crise financeira internacional (subprime EUA) naquele ano reverteu a trajetória crescente da produção física nos estados, sendo que, a partir de 2011, a indústria de transformação nos estados passou a assumir trajetória decrescente. As maiores quedas são observadas para os estados do Espírito Santo e Rio de Janeiro, coincidindo com a incerteza decorrente do cenário político e econômico vivenciado no país nos últimos anos (Impeachment presidencial, Operação Laja Jato, descontrole das contas públicas, dentre outros).

Gráfico 3 - Desempenho da produção física da indústria de transformação dos estados da região Sudeste, 2002 a 2017 (índice $2012=100$ )

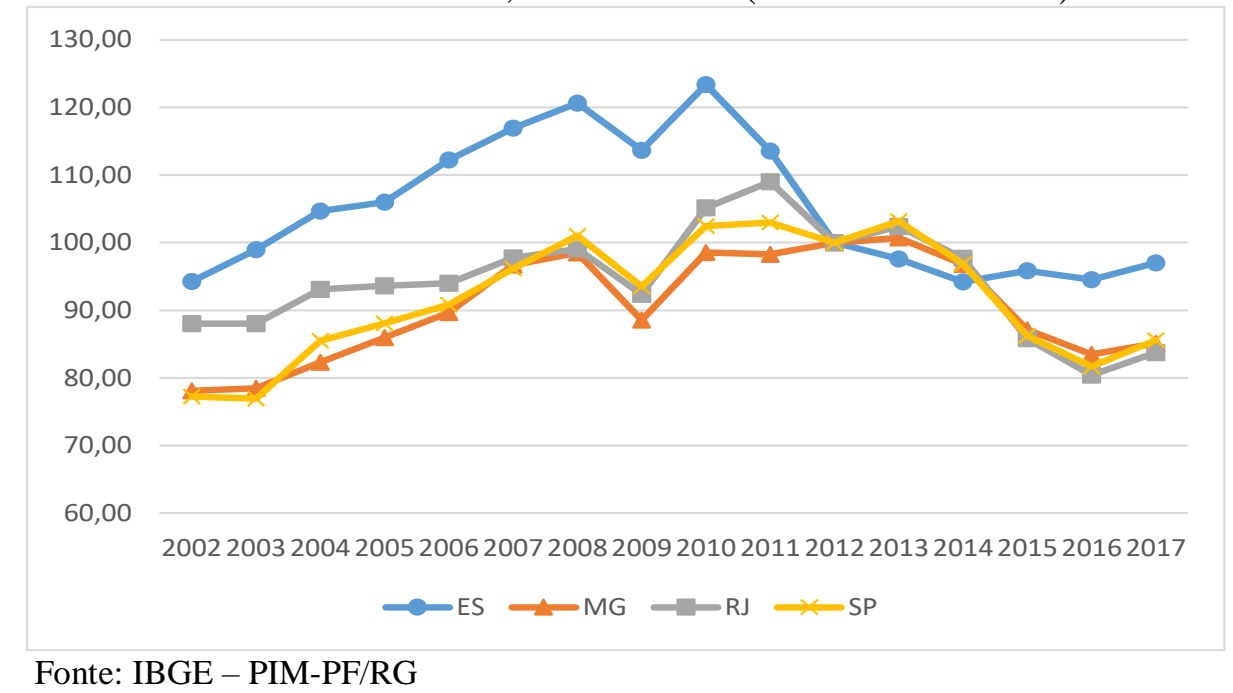

Por fim, considerando o conceito de desindustrialização refletido pelo problema da Doença Holandesa, o Gráfico 4 mostra a participação dos produtos manufaturados nas exportações totais de cada estado da região Sudeste no período 2000-2017.

Gráfico 4 - Participação dos produtos manufaturados nas exportações dos estados da região Sudeste, 2000 a 2017 (em \%)

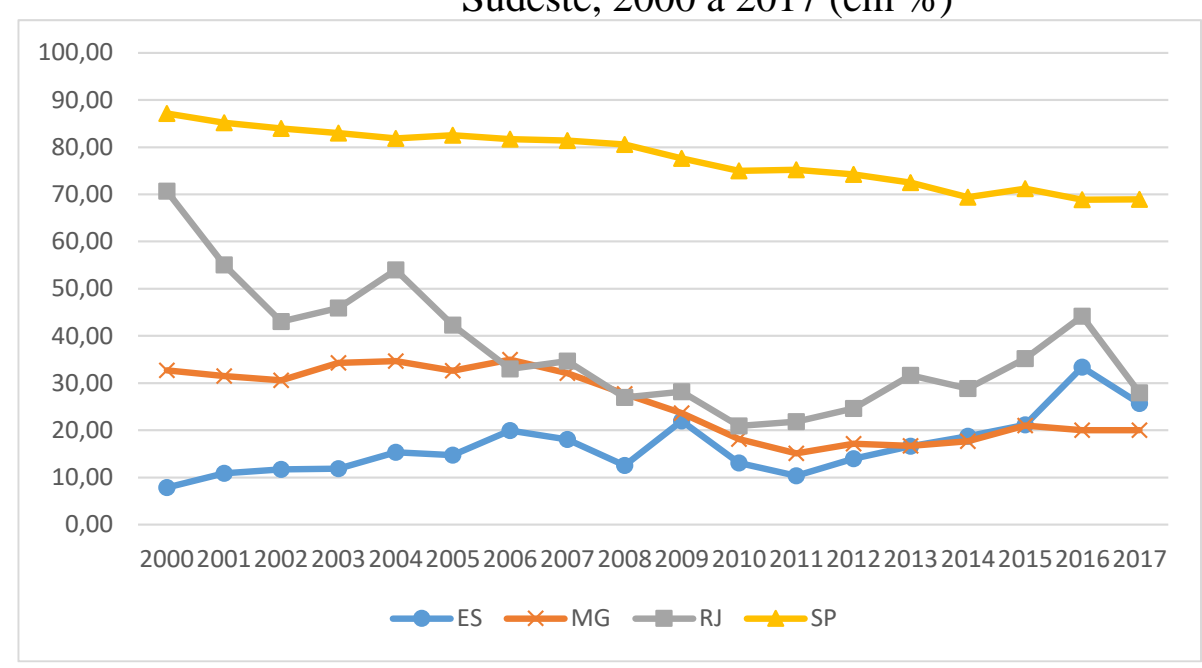

Fonte: MDIC 
Os dados assinalam que o Espírito Santo foi o único estado em que a indústria de transformação ganhou participação (17,8 p.p.) na pauta exportadora, embora o peso do setor seja o menor dentre os estados analisados (média de 16,5\%). São Paulo ainda é o estado com maior relevância dos produtos manufaturados nas exportações (média de $77,8 \%$ ), contudo perdeu participação de 18,1 p.p. destes bens na pauta. Em Minas Gerais, os produtos manufaturados corresponderam, em média, a $25,6 \%$ das exportações, e a perda de peso na pauta foi de 12,7 p.p.. A queda de participação das exportações de manufaturados foi mais expressiva no Rio de Janeiro (42,7 p.p.). Cabe ressaltar que as estruturas produtivas fluminense, mineira e espírito-santense são fortemente baseadas em recursos naturais (minério de ferro em Minas Gerais, e petróleo e gás natural no Rio de Janeiro), propiciando a especialização das exportações daqueles estados em bens primários.

Em síntese, os indicadores analisados evidenciam alguma desindustrialização nos estados do Sudeste brasileiro, sobretudo em São Paulo, cuja indústria de transformação possui o desempenho mais relevante, mas também o que apresenta as quedas mais significativas nos resultados de emprego, produto e exportações industriais. Em consequência, cabe analisar as possíveis influências de algumas variáveis apontadas pela literatura como condicionantes desse processo. Tais variáveis refletem os efeitos decorrentes da política econômica implementada no país no pós-Real (abertura comercial, prática de juros elevados e câmbio sobrevalorizado), além de um contexto de preços internacionais favoráveis à expansão dos bens primários, com prejuízo aos setores produtores de manufaturados. Tal investigação será efetivada na próxima seção do trabalho.

\section{Metodologia}

Este artigo objetiva investigar a hipótese de desindustrialização nos estados da região Sudeste brasileira, ao longo dos anos 2000, por meio dos efeitos da taxa de câmbio real, dos preços das commodities, da taxa de juros e do grau de abertura comercial sobre três indicadores de desempenho da indústria de transformação dos respectivos estados: produção, emprego e exportações de bens manufaturados. Para isso, avalia-se a existência de relações de longo prazo entre as variáveis mencionadas pela estimação de modelos Auto Regressivos de Defasagens Distribuídas (ARDL) aplicados à cointegração, como propostos por Pesaran e Shin (1999) e Pesaran et al. (2001).

A metodologia ARDL possui algumas vantagens em relação aos testes de cointegração em variáveis não estacionárias (tais como em Johansen, 1991; Phillips e Hansen, 1999; Engle e Granger, 1987) e aos modelos de Vetores Auto Regressivos (VAR). Primeiro, a técnica de cointegração proposta por Pesaran et al. (2001) pode ser aplicada em um conjunto de variáveis com diferentes ordens de integração, o que possibilita o tratamento de dados puramente $\mathrm{I}(0)$, puramente $\mathrm{I}(1)$, ou com as duas ordens de integração. Segundo, o teste de cointegração em modelos ARDL tende a ser mais eficiente para captar as relações de longo prazo em amostras pequenas de dados (PESARAN; SHIN, 1999). Por fim, um nível ótimo de defasagens pode ser determinado para cada uma das variáveis do modelo ARDL, por intermédio de um critério de seleção previamente escolhido (normalmente o critério de informação Akaike).

A abordagem ARDL consiste na verificação da existência de vetores de longo prazo entre um conjunto de variáveis. Confirmada esta relação, estimam-se os coeficientes de longo e curto prazos dos modelos, bem como a velocidade de ajustamento ao equilíbrio de longo prazo. Para isso, o modelo ARDL é estimado na forma de vetores de correção de erros (ARDL-ECM), podendo ser especificado como se segue:

$\Delta y_{t}=\alpha_{0}+\alpha_{1} \tau+\delta_{1} y_{t-1}+\delta_{2} x_{t-1}+\sum_{i=0}^{n} \phi_{1} \Delta y_{t-1}+\sum_{i=0}^{n} \phi_{1} \Delta x_{t-1}+\varepsilon_{t}$

em que $\Delta$ indica primeira diferença; $\alpha_{0}$ e $\alpha_{1}$ são termos de constante e tendência; $\delta_{\mathrm{i}}, i=1,2$, são parâmetros de longo prazo; $\phi_{\mathrm{i}}, i=1,2$, são parâmetros de curto prazo; $\varepsilon_{\mathrm{t}}$ é o termo de erro. 
O teste de cointegração desenvolvido por Pesaran et al. (2001) é um teste Wald (teste-F) para a verificação da significância conjunta dos parâmetros de longo prazo. Entretanto, sob a hipótese nula de não existência de cointegração, os valores críticos do teste Wald não possuem uma distribuição assintótica padrão para qualquer ordem de integração dos regressores. Para isso, Pesaran et al. (2001) fornecem uma banda de valores críticos, onde o nível inferior é calculado com a hipótese de que todas as variáveis do modelo ARDL são estacionárias e a banda superior com a hipótese de que todas as variáveis são I(1). Os modelos podem contar com a utilização (ou não) de intercepto e tendência.

Definida a banda de valores críticos, a estatística-F do teste Wald é comparada com ela. A hipótese nula é de não existência de vetores de cointegração $\left(H_{0}: \delta_{1}=\delta_{2}=0\right)$, e a hipótese alternativa é de existência de relação de longo prazo entre as variáveis do modelo $\left(H_{1}: \delta_{1} \neq \delta_{2} \neq 0\right)$. Se a estatística-F do teste Wald ficar abaixo da banda inferior de valores críticos, a hipótese nula não é rejeitada, ou seja, não há cointegração. Se a estatística-F for maior do que a banda superior de valores críticos, a hipótese nula é rejeitada (há cointegração). Por fim, se a estatística-F ficar dentro do intervalo de valores críticos, os resultados são inconclusivos.

A investigação proposta neste artigo envolve a estimação de três especificações de modelos ARDL aplicados à cointegração, sendo que cada especificação será estimada para os quatro estados da região Sudeste, conforme as seguintes equações ${ }^{3}$ :

- Modelo 1 - Variável Dependente: Produção (PIM), com dados mensais de 2002:01 a 2017:06

$\triangle P I M_{t}=\alpha_{0}+\alpha_{1} \tau+\delta_{1}$ PIM $_{t-1}+\delta_{2}$ TCREF $_{t-1}+\delta_{3}$ IPCOM $_{t-1}+\delta_{4}$ SELIC $_{t-1}+\delta_{5} A B E R T_{t-1}+$ $\sum_{i=0}^{n} \phi_{1} \Delta P I M_{t-1}+\sum_{i=0}^{p} \phi_{2} \Delta$ TCREF $_{t-1}+\sum_{i=0}^{q} \phi_{3} \Delta I P C O M_{t-1}+\sum_{i=0}^{r} \phi_{4} \Delta S E L I C_{t-1}+$ $\sum_{i=0}^{s} \phi_{5} \triangle A B E R T_{t-1}+\varepsilon_{t}$

- Modelo 2 - Variável Dependente: Emprego (EMP), com dados mensais de 2004:01 a 2017:06

$\triangle E M P_{t}=\alpha_{0}+\alpha_{1} \tau+\delta_{1} E M P_{t-1}+\delta_{2}$ TCREF $_{t-1}+\delta_{3}$ IPCOM $_{t-1}+\delta_{4}$ SELIC $_{t-1}+\delta_{5} A B E R T_{t-1}+$ $\sum_{i=0}^{n} \phi_{1} \Delta E M P_{t-1}+\sum_{i=0}^{p} \phi_{2} \Delta T C R E F_{t-1}+\sum_{i=0}^{q} \phi_{3} \Delta I P C O M_{t-1}+\sum_{i=0}^{r} \phi_{4} \Delta S E L I C_{t-1}+$ $\sum_{i=0}^{S} \phi_{5} \Delta A B E R T_{t-1}+\varepsilon_{t}$

- Modelo 3 - Variável Dependente: Exportações de manufaturados (XMANUF), com dados mensais de 2000:01 a 2017:06

$$
\begin{aligned}
& \triangle X M A N U F_{t}=\alpha_{0}+\alpha_{1} \tau+\delta_{1} X \text { MANUF }_{t-1}+\delta_{2} \text { TCREF }_{t-1}+\delta_{3} \text { IPCOM }_{t-1}+\delta_{4} \text { SELIC }_{t-1}+ \\
& \delta_{5} A B E R T_{t-1}+\sum_{i=0}^{n} \phi_{1} \Delta X M A N U F_{t-1}+\sum_{i=0}^{p} \phi_{2} \Delta T C R E F_{t-1}+\sum_{i=0}^{q} \phi_{3} \Delta \text { IPCOM }_{t-1}+ \\
& \sum_{i=0}^{r} \phi_{4} \Delta S E L I C_{t-1}+\sum_{i=0}^{S} \phi_{5} \Delta A B E R T_{t-1}+\varepsilon_{t}
\end{aligned}
$$

As variáveis utilizadas nos modelos podem ser especificadas como:

- PIM: Índice da produção física da indústria de transformação estadual $(2012=100)$. Fonte: Instituto Brasileiro de Geografia e Estatística - PIM-PF/RG.

- EMP: Índice do emprego da indústria de transformação estadual $(2012=100)$. Fonte: Cadastro Geral de Empregados e Desempregados - Ministério do Trabalho.

- XMANUF: Participação dos bens manufaturados nas exportações totais de cada estado (em $\%)$. Fonte: Ministério da Indústria, Comércio Exterior e Serviços.

\footnotetext{
${ }^{3}$ O período envolvido na estimação de cada modelo variou conforme a disponibilidade da base de dados utilizada
} 
- TCREF: Índice da taxa de câmbio real efetiva - exportações de manufaturados $(2010=100)$. Fonte: Instituto de Pesquisa Econômica Aplicada (IPEADATA).

- IPCOM: Índice de preços internacionais das commodities - geral (2005=100). Fonte: Fundo Monetário Internacional.

- SELIC: Taxa de juros Over-Selic (\% a.m.). Fonte: Banco Central do Brasil.

- ABERT: Grau de abertura comercial da economia, dado pela soma das exportações e importações em relação ao PIB brasileiro (em \%). Fonte: Banco Central do Brasil.

Todas as variáveis foram trabalhadas em logaritmo natural. Também foram incluídas duas variáveis dummies nas estimações, denominadas DCRISE (assumindo o valor 1 para todos os meses do ano de 2009), para captar os efeitos da crise norte-americana (subprime), e DLAVA (assumindo o valor 1 para os meses a partir de março de 2014), para captar a ocorrência da Operação Lava Jato e a instabilidade política e institucional decorrente no país. A inclusão dessas variáveis foi necessária para corrigir a instabilidade dos modelos (conforme os testes de estabilidade dos modelos CUSUM e CUSUMSQ).

A especificação dos modelos foi feita com base na literatura sobre desindustrialização nacional, em que autores como Bresser-Pereira (2007) e Oreiro e Feijó (2010) apontam a relevância da taxa de câmbio real e dos preços internacionais das commodities para sinalizar um processo de desindustrialização pela via da Doença Holandesa. Ademais, procurou-se incorporar as variáveis grau de abertura comercial e taxa de juros Selic nas estimações a fim de contemplar um possível processo de desindustrialização por meio das políticas econômicas adotadas no país, conforme argumentam Palma (2005) e Cano (2012).

Na evidência de desindustrialização, espera-se que a taxa de câmbio real esteja positivamente associada com os indicadores da indústria de transformação dos respectivos estados. Segundo Sonaglio (2011), a sobreapreciação cambial afeta negativamente a estrutura industrial, pois as empresas passam a importar os componentes que antes eram produzidos internamente e, em alguns casos, importam inclusive bens finais, eliminando estágios da cadeia produtiva. Porém, existe o argumento de que a apreciação real da taxa de câmbio poderia servir de incentivo à importação dos bens de capital, ampliando a competitividade da indústria, e, neste caso, favorecendo o desempenho da indústria de transformação.

De outro lado, espera-se que um comportamento altista dos preços internacionais das commodities exerça influência negativa sobre a produção física, o emprego e as exportações de bens manufaturados dos estados, visto que o contexto de preços favoráveis aos produtos primários seria propício à especialização da economia em setores intensivos em recursos naturais, com menor valor relativo agregado, implicando menor direcionamento de recursos produtivos (capital, trabalho e tecnologia) para a atividade de transformação.

Também se espera uma influência negativa da taxa de juros SELIC, pois taxas menores beneficiam os investimentos na capacidade produtiva, ampliando a produção, o emprego e as exportações de bens manufaturados. Por fim, os efeitos da abertura comercial do país podem ser ambíguos, pois o maior grau de abertura pode representar substituição de produção interna por bens industriais importados, mas também pode estar relacionado à importação de máquinas, equipamentos e insumos utilizados na produção industrial, estimulando o desempenho favorável da atividade de transformação nos estados. 


\section{Resultados}

Previamente às estimações dos modelos ARDL aplicados à cointegração, cabe avaliar a ordem de integração das variáveis utilizadas, visto que o método é adequado à estimação com variáveis com diferentes ordens de integração. Portanto, foram aplicados os testes tradicionais de raiz unitária Augmented Dickey-Fuller (ADF), Philips-Perron (PP) e Kwiatkowski-Phillips-Schmidt-Shin (KPSS). A Tabela 1 sintetiza os resultados destes testes, os quais indicam que algumas variáveis são consideradas I(0), enquanto outras são I(1), o que sinaliza os benefícios da utilização da metodologia proposta.

Tabela 1 - Testes de raiz unitária

\begin{tabular}{lcccccc}
\hline & $\mathrm{ADF}$ & $\mathrm{k}$ & $\mathrm{PP}$ & $\mathrm{k}$ & $\mathrm{KPSS}$ & $\mathrm{k}$ \\
\hline Produção Industrial ES & $-3.39^{* *}$ & 1 & $-4.04^{*}$ & 4 & 0.46 & 10 \\
Produção Industrial MG & -2.10 & 12 & $-4.32^{*}$ & 4 & $0.65^{* *}$ & 9 \\
Produção Industrial RJ & -1.20 & 12 & $-4.25^{*}$ & 1 & 0.32 & 10 \\
Produção Industrial SP & -2.25 & 13 & $-4.25^{*}$ & 6 & $0.59^{* *}$ & 9 \\
Emprego Industrial ES & -2.00 & 13 & $-3.83^{*}$ & 1 & 1.29 & 10 \\
Emprego Industrial MG & -1.95 & 13 & $-3.33^{* *}$ & 2 & 1.08 & 10 \\
Emprego Industrial RJ & -2.00 & 13 & -1.99 & 9 & 1.08 & 10 \\
Emprego Industrial SP & -1.56 & 13 & -2.53 & 3 & $0.59^{* *}$ & 10 \\
Exportações Manuf. ES & $-3.26^{* *}$ & 2 & $-8.00^{*}$ & 8 & $0.94^{*}$ & 10 \\
Exportações Manuf. MG & -1.48 & 2 & -2.71 & 16 & $1.44^{*}$ & 11 \\
Exportações Manuf. RJ & $-3.16^{* *}$ & 2 & -7.98 & 8 & $1.31^{*}$ & 10 \\
Exportações Manuf. SP & 0.25 & 11 & -2.66 & 5 & $1.79 *$ & 11 \\
Taxa de câmbio real & -1.29 & 1 & -1.24 & 7 & 0.38 & 11 \\
Preços das commodities & -1.68 & 1 & -1.71 & 6 & $1.16^{*}$ & 11 \\
Taxa de Juros SELIC & -1.63 & 12 & -2.27 & 5 & $1.09^{*}$ & 11 \\
Grau de abertura & -2.14 & 14 & -5.67 & $1 *$ & $0.59^{* *}$ & 9 \\
\hline
\end{tabular}

Fonte: Elaboração própria a partir dos resultados do Eviews 9.5

Estimações com constante

$\mathrm{k}$ : número de defasagens

Valores críticos testes ADF e PP: $1 \%(-3.47)$ e $5 \%$ (-2.88)

Valores críticos teste KPSS: $1 \%(0.74)$ e $5 \%(0.46)$

(*) e (**) rejeição de $\mathrm{H}_{0}$ a $1 \%$ e $5 \%$ de significância

ADF e PP: $\mathrm{H}_{0}$ : Tem raiz unitária

KPSS: $\mathrm{H}_{0}$ : Não tem raiz unitária

Ainda, antes de se efetuar as análises de curto e longo prazos, os resultados das estimações ARDL passaram por alguns testes de diagnóstico. Estes incluem a análise de autocorrelação dos resíduos (LM Autocorrelation Test), cuja hipótese é de não existência de autocorrelação serial. A Tabela 2, na sequência, exibe os resultados desse teste, bem como as defasagens selecionadas para cada variável dos modelos nas suas diversas especificações, sendo utilizadas quatro defasagens e o critério de informação de Akaike (AIC) como base de seleção. Cabe destacar que todos os modelos estimados passaram nos testes de ausência de autocorrelação serial (não rejeição da hipótese nula).

Também foram estimados os testes de estabilidade dos modelos CUSUM (Cumulative Sum) e CUSUMSQ (Cumulative Sum of Squares), os quais permitem avaliar a constância dos coeficientes dos modelos. A instabilidade nos parâmetros é diagnosticada se a soma cumulativa dos resíduos ultrapassa os limites da área das linhas críticas a 5\% de significância estatística, o que sinaliza a influência de quebra estrutural nas estimações. No caso das estimações dos modelos para os estados brasileiros, os testes CUSUM e CUSUMSQ apresentaram estabilidade com a adição das variáveis dummies DCRISE e DLAVA. ${ }^{4}$

\footnotetext{
${ }^{4}$ Por questão de espaço, os gráficos dos testes CUSUM e CUSUMSQ não serão reportados. Contudo, os resultados podem ser solicitados à autoria do artigo.
} 
Tabela 2 - Estimativas dos modelos ARDL

\begin{tabular}{|c|c|c|c|}
\hline Estados & $\begin{array}{l}\text { Defasagens } \\
\text { Selecionadas }\end{array}$ & $\begin{array}{l}\text { ARDL Variáveis Significativas } \\
\text { (Defasagens significativas) }\end{array}$ & $\begin{array}{c}\text { Teste LM } \\
\text { Autocorrelação } \\
\text { [Prob.] }\end{array}$ \\
\hline \multicolumn{4}{|c|}{ Modelo 1: Variável dependente - Produção } \\
\hline Espírito Santo & $(4,0,2,1,4)$ & PIMES (-1); TCREF (-1); IPCOM(-2); $\operatorname{SELIC~(-3);~ABERT(-~}$ & $\begin{array}{c}2,5840 \\
{[0,0786]}\end{array}$ \\
\hline Minas Gerais & $(4,0,1,4,0)$ & $\begin{array}{c}\text { PIMMG (-1, -2, -3, -4); TCREF (-1); IPCOM (-1); } \operatorname{SELIC~(-1,~} \\
-2,-3,-4 .-5) ; \operatorname{ABERT}(-1)\end{array}$ & $\begin{array}{c}3,0754 \\
{[0,0500]}\end{array}$ \\
\hline Rio de Janeiro & $(2,4,2,4,2)$ & $\begin{array}{l}\text { PIMRJ }(-1,-2) ; \operatorname{IPCOM}(-1,-2) ; \operatorname{SELIC~}(-1,-2,-3,-4,-5) ; \\
\operatorname{ABERT}(-1,-2)\end{array}$ & $\begin{array}{c}2,1824 \\
{[0,1161]}\end{array}$ \\
\hline São Paulo & $(4,0,0,4,0)$ & $\begin{array}{l}\text { PIMSP }(-1,-4) ; \text { TCREF }(-1) ; \operatorname{IPCOM}(-1) ; \operatorname{SELIC}(-1,-2,-3,- \\
4,-5) ; \operatorname{ABERT}(-1)\end{array}$ & $\begin{array}{c}2,2194 \\
{[0,1119]}\end{array}$ \\
\hline \multicolumn{4}{|c|}{ Modelo 2: Variável dependente - Emprego } \\
\hline Espírito Santo & $(4,1,0,4,2)$ & $\begin{array}{l}\operatorname{EMPES}(-1,-4) ; \operatorname{TCREF}(-1 ;-2) ; \operatorname{IPCOM}(-1) ; \operatorname{SELIC}(-4,-5) ; \\
\operatorname{ABERT}(-3)\end{array}$ & $\begin{array}{c}0,3003 \\
{[0,7410]}\end{array}$ \\
\hline Minas Gerais & $(4,0,0,4,2)$ & EMPMG(-1, -2, -4); IPCOM(-1); SELIC $(-1,-4) ; \operatorname{ABERT}(-3)$ & $\begin{array}{c}1,5441 \\
{[0,2171]}\end{array}$ \\
\hline Rio de Janeiro & $(4,0,0,3,2)$ & EMPRJ $(-1,-3,-4) ; \operatorname{IPCOM}(-1) ;$ SELIC $(-1,-4) ;$ ABERT (-3) & $\begin{array}{c}0,0403 \\
{[0,9605]}\end{array}$ \\
\hline São Paulo & $(4,1,0,4,2)$ & $\begin{array}{l}\operatorname{EMPSP}(-1,-2,-4) ; \operatorname{TCREF}(-2) ; \operatorname{IPCOM}(-1) ; \operatorname{SELIC}(-1,-4,- \\
5) ; \operatorname{ABERT}(-3)\end{array}$ & $\begin{array}{c}0,1252 \\
{[0,8824]}\end{array}$ \\
\hline \multicolumn{4}{|c|}{ Modelo 3: Variável dependente - Exportações } \\
\hline Espírito Santo & $(3,0,0,0,1)$ & XMANUFES $(-1,-2,-3)$ & $\begin{array}{c}0,6747 \\
{[0,5105]}\end{array}$ \\
\hline Minas Gerais & $(3,3,1,4,2)$ & $\begin{array}{l}\text { XMANUFMG(-1, -3); TCREF (-3); IPCOM(-2); } \operatorname{SELIC~(-5);~} \\
\qquad \operatorname{ABERT}(-3)\end{array}$ & $\begin{array}{c}1,3389 \\
{[0,2647]}\end{array}$ \\
\hline Rio de Janeiro & $(2,1,2,4,3)$ & $\begin{array}{c}\text { XMANUFRJ (-2); TCREF (-1); IPCOM }(-1,-2,-3) \text {; SELIC (- } \\
3,-5) ; \operatorname{ABERT}(-4)\end{array}$ & $\begin{array}{c}0,4337 \\
{[0,6488]}\end{array}$ \\
\hline São Paulo & $(4,2,0,4,4)$ & $\begin{array}{c}\text { XMANUFSP }(-2,-4) ; \operatorname{IPCOM}(-1) ; \operatorname{SELIC}(-1,-4,-5) ; \\
\text { ABERT }(-5)\end{array}$ & $\begin{array}{c}1,0509 \\
{[0,3517]}\end{array}$ \\
\hline
\end{tabular}

Fonte: Elaboração própria a partir das saídas do Eviews 9.5.

Após assegurar que as estimativas não possuíam problemas de correlação serial e que a dinâmica dos parâmetros é estável, a existência de cointegração (relação de longo prazo) entre as variáveis foi examinada a partir da aplicação dos Testes de Limites (ARDL Bounds Tests), que consiste no teste de Wald (F-test) para avaliar a significância conjunta dos parâmetros de longo prazo dos modelos. A Tabela 3 sistematiza os resultados obtidos levando em conta os valores críticos de Pesaran et al. (2001). Os testes indicaram que as estatísticas-F foram maiores do que os valores críticos (a 5\%), sinalizando a rejeição da hipótese de não cointegração em todos os modelos para os estados da região Sudeste. Em outras palavras, confirma-se a existência de cointegração de longo prazo entre as variáveis analisadas, indicando que as variáveis explicativas têm papel importante para explicar o desempenho da produção, do emprego e das exportações de bens manufaturados dos estados da região Sudeste. 
Tabela 3 - Teste de cointegração (Bounds limits)

\begin{tabular}{|c|c|c|c|c|c|c|c|c|}
\hline \multirow{3}{*}{ Estados } & \multirow{2}{*}{\multicolumn{3}{|c|}{ F- Statistics }} & \multicolumn{4}{|c|}{ Valores críticos } & \multirow{3}{*}{$\begin{array}{c}\text { Cointegração } \\
\text { de longo } \\
\text { prazo? }\end{array}$} \\
\hline & & & & \multicolumn{2}{|c|}{$\mathrm{I}(0)$ Bound } & \multicolumn{2}{|c|}{ I(1) Bound } & \\
\hline & Modelo 1 & Modelo 2 & Modelo 3 & $10 \%$ & $5 \%$ & $10 \%$ & $5 \%$ & \\
\hline Espírito Santo & 3,63 & 4,59 & 12,19 & 2,2 & 2,56 & 3,09 & 3,49 & Sim \\
\hline Minas Gerais & 15,93 & 3,11 & 15,29 & 2,2 & 2,56 & 3,09 & 3,49 & Sim \\
\hline Rio de Janeiro & 6,89 & 9,38 & 9,64 & 2,2 & 2,56 & 3,09 & 3,49 & Sim \\
\hline São Paulo & 22,06 & 6,09 & 16,93 & 2,2 & 2,56 & 3,09 & 3,49 & Sim \\
\hline
\end{tabular}

Fonte: Elaboração própria a partir das saídas do Eviews 9.5.

Nota: $\mathrm{H}_{0}$ : não há relação de longo prazo.

Contudo, a análise do papel de cada variável explicativa em um contexto de longo prazo se torna necessária. Ademais, tais relações de longo prazo não significam a inexistência de possíveis choques de curto prazo, os quais também devem ser avaliados. Assim, na sequência, foram estimados os coeficientes de cointegração de longo prazo para todos os modelos considerados. A Tabela 4 reporta os resultados obtidos.

As evidências revelam que os coeficientes que foram estatisticamente significativos para a taxa de câmbio real efetiva apresentaram sinais negativos em todos os modelos estimados. Isto sugere que a produção, o emprego e as exportações da indústria de transformação dos estados do Sudeste no longo prazo não foram prejudicados pela apreciação cambial vivenciada no país em boa parte dos anos 2000. Uma possível justificativa se relaciona ao fato de que a atividade industrial na região se mostra dependente da importação de insumos, que se tornam mais baratos em um cenário de moeda doméstica valorizada, reduzindo custos de produção, e beneficiando, portanto, a produção, o emprego e os setores exportadores. Além disso, no contexto de apreciação cambial, a produção de bens manufaturados pode ter sido direcionada para o mercado interno, enquanto as exportações passaram a ser dominadas por produtos de origem primária.

Os coeficientes dos preços das commodities foram negativos para a produção do Espírito Santo e para as exportações de Rio de Janeiro e São Paulo. Assim, nesses estados, há sinalização de deslocamento de recursos produtivos da atividade industrial para os setores produtores de bens primários, e estímulo aos setores exportadores de commodities, que passam a apresentar maior rentabilidade, com prejuízo à indústria de transformação. Contudo, a variável apresentou sinal positivo para a produção em Minas Gerais e São Paulo, e para o emprego em todos os estados. No caso de Minas Gerais, isso se atrela às características de sua indústria baseada em recursos naturais e trabalho. No caso de São Paulo, embora predomine indústrias de média-alta e média tecnologia, há o avanço das atividades também baseadas em recursos naturais e trabalho ao longo do tempo. No emprego, o contexto de preços internacionais elevados para os bens primários também pode ter se refletido no aumento de postos de trabalho nos setores de baixa tecnologia ou intensivos em trabalho pouco qualificado, de menor produtividade.

Os coeficientes da taxa de juros SELIC foram significativos, com sinal negativo, para explicar a produção de Minas Gerais e São Paulo, o emprego em todos os estados, e as exportações de bens manufaturados do Rio de Janeiro. Deste modo, sugere-se que um ambiente menos favorável para a tomada de recursos nos mercados financeiros acaba por desestimular a ampliação da capacidade produtiva da indústria de transformação dos estados, com efeitos negativos, sobretudo, para o emprego e as exportações.

O grau de abertura comercial apresentou efeitos positivos sobre a produção de Minas Gerais e São Paulo, e para as exportações de Minas Gerais, São Paulo e Rio de Janeiro. Esse resultado sugere que a abertura comercial pode ter favorecido a modernização da atividade industrial daqueles estados pela importação de máquinas e equipamentos de capital, além de insumos industriais mais baratos, reduzindo custos e favorecendo a competitividade no mercado externo. Todavia, nos modelos para o emprego, os efeitos da abertura comercial foram negativos. Neste caso, a abertura da economia pode ter implicado em substituição da produção doméstica por bens industriais finais importados mais 
baratos, contribuindo para a quebra de empresas que não conseguiram se modernizar e reduzir custos, provocando o desemprego.

Tabela 4 - Coeficientes de longo prazo

\begin{tabular}{|c|c|c|c|c|}
\hline & \multicolumn{4}{|c|}{ Modelo 1 - Produção } \\
\hline & Espírito Santo & Minas Gerais & Rio de Janeiro & São Paulo \\
\hline & $\begin{array}{l}\text { Coefic. } \\
\text { [Prob.] } \\
\end{array}$ & $\begin{array}{l}\text { Coefic. } \\
{[\text { Prob.] }}\end{array}$ & $\begin{array}{l}\text { Coefic. } \\
\text { [Prob.] } \\
\end{array}$ & $\begin{array}{l}\text { Coefic. } \\
\text { [Prob.] }\end{array}$ \\
\hline TCREF & $\begin{array}{c}-0,5763 \\
{[0,0035]}\end{array}$ & $\begin{array}{c}-\mathbf{- 0 , 1 1 1 9} \\
{[0,0200]}\end{array}$ & $\begin{array}{c}-0,0942 \\
{[0,2051]}\end{array}$ & $\begin{array}{c}0,1693 \\
{[0,0008]}\end{array}$ \\
\hline IPCOM & $\begin{array}{c}-0,3561 \\
{[0,0334]}\end{array}$ & $\begin{array}{c}0,1032 \\
{[0,0063]}\end{array}$ & $\begin{array}{c}0,0600 \\
{[0,2652]}\end{array}$ & $\begin{array}{c}0,0996 \\
{[0,0104]}\end{array}$ \\
\hline SELIC & $\begin{array}{c}-0.2080 \\
{[0,1729]}\end{array}$ & $\begin{array}{c}-0,1390 \\
{[0,0001]}\end{array}$ & $\begin{array}{c}-0,0871 \\
{[0,1178]}\end{array}$ & $\begin{array}{c}-0,1470 \\
{[0,0001]}\end{array}$ \\
\hline ABERT & $\begin{array}{c}0,1598 \\
{[0,5458]}\end{array}$ & $\begin{array}{c}0,1379 \\
{[0,0081]}\end{array}$ & $\begin{array}{c}0,0051 \\
{[0,9560]}\end{array}$ & $\begin{array}{c}0,1723 \\
{[0,0014]}\end{array}$ \\
\hline $\mathrm{C}$ & $\begin{array}{c}8,6759 \\
{[0,0000]}\end{array}$ & $\begin{array}{c}4,1451 \\
{[0,0000]}\end{array}$ & $\begin{array}{c}4,7251 \\
{[0,0000]}\end{array}$ & $\begin{array}{c}4,3534 \\
{[0,0000]}\end{array}$ \\
\hline & \multicolumn{4}{|c|}{ Modelo 2 - Emprego } \\
\hline & Espírito Santo & Minas Gerais & Rio de Janeiro & São Paulo \\
\hline & $\begin{array}{l}\text { Coefic. } \\
\text { [Prob.] }\end{array}$ & $\begin{array}{l}\text { Coefic. } \\
\text { [Prob.] }\end{array}$ & $\begin{array}{l}\text { Coefic. } \\
\text { [Prob.] }\end{array}$ & $\begin{array}{l}\text { Coefic. } \\
\text { [Prob.] }\end{array}$ \\
\hline TCREF & $\begin{array}{c}0,0549 \\
{[0,3590]}\end{array}$ & $\begin{array}{c}0,0335 \\
{[0,4884]}\end{array}$ & $\begin{array}{c}-0,1555 \\
{[0,3032]}\end{array}$ & $\begin{array}{c}-\mathbf{- 0 , 0 9 0 5} \\
{[0,0140]}\end{array}$ \\
\hline IPCOM & $\begin{array}{c}0,2062 \\
{[0,0000]}\end{array}$ & $\begin{array}{c}0,1898 \\
{[0,0000]}\end{array}$ & $\begin{array}{c}0,2123 \\
{[0,0217]}\end{array}$ & $\begin{array}{c}0,1168 \\
{[0,0001]}\end{array}$ \\
\hline SELIC & $\begin{array}{c}-0,0873 \\
{[0,0310]}\end{array}$ & $\begin{array}{c}-0,1149 \\
{[0,0005]}\end{array}$ & $\begin{array}{c}-0,1356 \\
{[0,1015]}\end{array}$ & $\begin{array}{c}-0.0636 \\
{[0,0090]}\end{array}$ \\
\hline ABERT & $\begin{array}{c}-0,1825 \\
{[0,0100]}\end{array}$ & $\begin{array}{c}-0,2360 \\
{[0,0001]}\end{array}$ & $\begin{array}{c}-1,1803 \\
{[0,2347]}\end{array}$ & $\begin{array}{c}-0,1760 \\
{[0,0001]}\end{array}$ \\
\hline \multirow[t]{4}{*}{$\mathrm{C}$} & $\begin{array}{c}-3,7883 \\
{[0,0000]}\end{array}$ & $\begin{array}{c}4,1213 \\
{[0,0000]}\end{array}$ & $\begin{array}{c}4,8020 \\
{[0,0000]}\end{array}$ & $\begin{array}{c}4,9217 \\
{[0,0000]}\end{array}$ \\
\hline & \multicolumn{4}{|c|}{ Modelo 3 - Exportações } \\
\hline & Espírito Santo & Minas Gerais & Rio de Janeiro & São Paulo \\
\hline & $\begin{array}{l}\text { Coefic. } \\
\text { [Prob.] }\end{array}$ & $\begin{array}{l}\text { Coefic. } \\
\text { [Prob.] }\end{array}$ & $\begin{array}{l}\text { Coefic. } \\
\text { [Prob.] }\end{array}$ & $\begin{array}{l}\text { Coefic. } \\
\text { [Prob.] }\end{array}$ \\
\hline TCREF & $\begin{array}{c}0,3687 \\
{[0,2887]}\end{array}$ & $\begin{array}{c}-0,0994 \\
{[0,7393]}\end{array}$ & $\begin{array}{c}-0,4696 \\
{[0,0292]}\end{array}$ & $\begin{array}{c}-0,1926 \\
{[0,0000]}\end{array}$ \\
\hline IPCOM & $\begin{array}{c}-0,0253 \\
{[0,9120]}\end{array}$ & $\begin{array}{c}-0,3133 \\
{[0,1335]}\end{array}$ & $\begin{array}{c}-1,1122 \\
{[0,0000]}\end{array}$ & $\begin{array}{c}-0,1257 \\
{[0,0000]}\end{array}$ \\
\hline SELIC & $\begin{array}{c}-0,2902 \\
{[0,3817]}\end{array}$ & $\begin{array}{c}0,2654 \\
{[0,3945]}\end{array}$ & $\begin{array}{c}-0,5324 \\
{[0,0164]}\end{array}$ & $\begin{array}{c}0.0072 \\
{[0,8613]}\end{array}$ \\
\hline ABERT & $\begin{array}{c}0,7394 \\
{[0,1975]}\end{array}$ & $\begin{array}{c}1,3241 \\
{[0,0142]}\end{array}$ & $\begin{array}{c}1,0384 \\
{[0,0111]}\end{array}$ & $\begin{array}{c}0,3112 \\
{[0,0003]}\end{array}$ \\
\hline $\mathrm{C}$ & $\begin{array}{c}-1,2339 \\
{[0,5637]}\end{array}$ & $\begin{array}{c}1,1823 \\
{[0,5511]}\end{array}$ & $\begin{array}{c}8,0004 \\
{[0,0000]}\end{array}$ & $\begin{array}{c}4,9655 \\
{[0,0000]}\end{array}$ \\
\hline
\end{tabular}

Fonte: Elaboração própria a partir das saídas do Eviews 9.5.

O próximo passo consistiu em estimar os ajustamentos de curto prazo, via mecanismo de correção de erros (ECM) para os modelos ARDL considerados. Isso se faz necessário tendo em vista que os desequilíbrios de curto prazo podem ser vistos como um processo de ajustamento ao equilíbrio de longo prazo. Todavia, a velocidade de ajustamento a tal equilíbrio pode ser mais rápida ou mais lenta, dependendo das características dos estados. A maior (menor) velocidade de ajustamento significa que as relações de equilíbrio entre as variáveis retornam ao estado estável mais rápido (lento).

A Tabela 5 sistematiza os resultados ECM para os modelos ARDL estimados, bem como as variáveis que foram estatisticamente significantes para a dinâmica de curto prazo. Verifica-se que os 
sinais do Termo de Correção de Erro $\left(\mathrm{ECM}_{\mathrm{t}-1}\right)$ foram negativos e significativos em todas as estimativas. Os resultados para o Modelo 1 (produção) indicam que o estado de São Paulo possui a maior velocidade de ajustamento, o que significa que, para este estado, o processo de ajustamento é bem rápido, pois $86 \%$ dos choques são corrigidos em um mês. O estado com menor velocidade de ajustamento é o Espírito Santo (24\%). No Modelo 3 (exportações), o estado do Rio de Janeiro é o que se ajusta mais rapidamente (67\%), e Minas Gerais, o de ajustamento mais lento (18\%). Nota-se que no Modelo 2 (emprego), todos os estados possuem baixa velocidade de ajustamento dos choques das variáveis no curto prazo ao equilíbrio de longo prazo (menos de $20 \%$ ).

Tabela 5 - Dinâmica de curto prazo: correção de erros e variáveis significativas

\begin{tabular}{|c|c|c|c|c|c|c|}
\hline & \multicolumn{2}{|c|}{ Modelo 1 - Produção } & \multicolumn{2}{|c|}{ Modelo 2 - Emprego } & \multicolumn{2}{|c|}{ Modelo 3 - Exportações } \\
\hline Estados & $\begin{array}{c}\text { ECM }(-1) \\
\text { [Prob.] }\end{array}$ & $\begin{array}{c}\text { Variáveis } \\
\text { Significativas }\end{array}$ & $\begin{array}{c}\text { ECM(-1) } \\
\text { [Prob.] }\end{array}$ & $\begin{array}{c}\text { Variáveis } \\
\text { Significativas }\end{array}$ & $\begin{array}{c}\operatorname{ECM}(-1) \\
\text { [Prob.] }\end{array}$ & $\begin{array}{c}\text { Variáveis } \\
\text { Significativas }\end{array}$ \\
\hline Espírito Santo & $\begin{array}{l}-0,2449 \\
{[0,0000]}\end{array}$ & $\begin{array}{l}\text { PIMES }(-1,-2) \\
\text { IPCOM }(-2) \\
\text { SELIC }(-1) \\
\text { ABERT }(-1,-3, \\
-4)\end{array}$ & $\begin{array}{l}-0,1170 \\
{[0,0000]}\end{array}$ & $\begin{array}{l}\text { EMPES }(-3) \\
\text { TCREF }(-1) \\
\text { IPCOM }(-2) \\
\text { SELIC }(-3,-4) \\
\text { ABERT }(-2) \\
\end{array}$ & $\begin{array}{l}-0,4042 \\
{[0,0000]}\end{array}$ & $\begin{array}{c}\text { XMANUFES (-1, } \\
-2)\end{array}$ \\
\hline Minas Gerais & $\begin{array}{l}-0,7776 \\
{[0,0000]}\end{array}$ & $\begin{array}{c}\text { PIMMG }(-1,-2, \\
-3) \\
\text { IPCOM }(-1) \\
\text { SELIC }(-1,-3, \\
-4)\end{array}$ & $\begin{array}{l}-0,1365 \\
{[0,0000]}\end{array}$ & $\begin{array}{c}\text { EMPMG }(-2,-3) \\
\text { SELIC }(-1,-2, \\
-3) \\
\text { ABERT }(-2)\end{array}$ & $\begin{array}{l}-0,1798 \\
{[0,0000]}\end{array}$ & $\begin{array}{c}\text { XMANUFMG }(-1 \text {, } \\
-2) \\
\text { TCREF }(-3) \\
\text { SELIC }(-3,-4) \\
\text { ABERT }(-2)\end{array}$ \\
\hline Rio de Janeiro & $\begin{array}{l}-0,4816 \\
{[0,0000]}\end{array}$ & $\begin{array}{c}\text { PIMRJ }(-1) \\
\text { IPCOM }(-1,-2) \\
\text { SELIC }(-1,-3,- \\
4) \\
\text { ABERT }(-1) \\
\end{array}$ & $\begin{array}{l}-0,0263 \\
{[0,0000]}\end{array}$ & $\begin{array}{c}\text { EMPRJ }(-1,-3) \\
\text { SELIC }(-1,-2, \\
-3) \\
\text { ABERT }(-2)\end{array}$ & $\begin{array}{l}-0,6760 \\
{[0,0000]}\end{array}$ & $\begin{array}{c}\text { XMANUFRJ }(-1) \\
\text { TCREF }(-1) \\
\text { SELIC }(-3) \\
\text { ABERT }(-3)\end{array}$ \\
\hline São Paulo & $\begin{array}{l}-0,8600 \\
{[0,0000]}\end{array}$ & $\begin{array}{l}\text { PIMSP }(-1,-2, \\
-3) \\
\text { SELIC }(-1,-2, \\
-3)\end{array}$ & $\begin{array}{l}-0,1852 \\
{[0,0000]}\end{array}$ & $\begin{array}{c}\operatorname{EMPSP}(-2,-3) \\
\operatorname{SELIC}(-2,-3) \\
\operatorname{ABERT}(-2)\end{array}$ & $\begin{array}{l}-0,4169 \\
{[0,0000]}\end{array}$ & $\begin{array}{c}\text { XMANUFSP }(-1, \\
-2,-3) \\
\text { SELIC }(-1) \\
\text { ABERT }(-2)\end{array}$ \\
\hline
\end{tabular}

Fonte: Elaboração própria a partir das saídas do Eviews 9.5.

A Tabela 5 também registra quais variáveis foram relevantes para explicar a dinâmica de curto prazo nos modelos estimados, indicando que não há uma homogeneidade dos resultados entre os estados do Sudeste. Os choques de curto prazo dos valores defasados das variáveis de produção, emprego e exportações de cada estado, em geral, são significativos para explicar o comportamento daquelas variáveis em todos os modelos estimados. Dentre as variáveis explicativas analisadas, notase maior relevância dos choques de curto prazo das variáveis relacionadas ao contexto das políticas liberalizantes implementadas no país - taxa de juros SELIC e grau de abertura - para explicar os ajustamentos ao equilíbrio de longo prazo na produção, emprego e exportações de bens manufaturados nos diversos estados. Já os choques da taxa de câmbio real efetiva só foram relevantes no modelo do emprego no Espírito Santo e das exportações em Minas Gerais e no Rio de Janeiro, ao passo que os preços das commodities contribuíram para explicar o processo de ajustamento da produção dos estados (exceto em São Paulo) e do emprego no Espírito Santo, não sendo relevantes para os modelos referentes às exportações de bens manufaturados em nenhum dos estados do Sudeste. 


\section{Considerações Finais}

Este artigo analisou o desempenho da produção, do emprego e das exportações da indústria de transformação dos estados da região Sudeste brasileira, conforme os principais conceitos de desindustrialização apontados pela literatura econômica, a fim de obter evidências de perda de relevância da atividade no âmbito regional ao longo dos anos 2000, e suas possíveis causas. Neste sentido, verificou-se perda de participação da indústria de transformação no valor adicionado ao PIB estadual e, mais recentemente (após 2010), na produção física, além de reduzir também o peso do setor na geração de emprego e na pauta exportadora, indicando sinais preliminares de desindustrialização nos estados do Sudeste.

Cabe destacar que, inclusive, o estado de São Paulo, que se caracteriza pela alta participação dos bens manufaturados na produção, no emprego e no comércio exterior, vem perdendo relevância da atividade de transformação nos indicadores industriais. Para Minas Gerais, Rio de Janeiro e Espírito Santo, os indicadores se mostram relativamente menos preocupantes. Tais estados possuem estruturas produtivas baseadas na exploração de recursos naturais, assim, o contexto favorável de preços e demanda externa para os produtos primários, ao longo dos anos 2000, pode ter contribuído para estimular a atividade industrial local.

Para tentar justificar a perda de desempenho da indústria de transformação dos estados do Sudeste, este artigo utilizou a metodologia ARDL de cointegração para investigar os efeitos da taxa de câmbio real, dos preços das commodities, da abertura comercial e da taxa de juros sobre os indicadores industriais analisados. Os resultados econométricos revelaram que a deterioração da atividade industrial de transformação dos estados não se mostrou explicada pela condição cambial, visto que os choques da taxa de câmbio real tiveram efeitos negativos sobre boa parte dos indicadores. Isso sinaliza que os estados podem ter sido beneficiados pela valorização da moeda doméstica em decorrência do fato de que importam grande quantidade de insumos industriais. Ainda, a produção pode ter sido direcionada para o mercado interno, e, assim, os estados foram menos dependentes de um câmbio favorável (depreciado).

Os choques dos preços internacionais das commodities também não se mostraram prejudiciais à produção (exceto no Espírito Santo) e ao emprego, sendo negativos apenas para as exportações de Rio de Janeiro e São Paulo. Este resultado pode ser atrelado à natureza da indústria de transformação dos estados do Sudeste (exceto São Paulo), baseada principalmente na atividade metalúrgica e petrolífera, que é estimulada pelo contexto de preços elevados para tais commodities (minerais e petróleo).

Os choques da abertura comercial prejudicaram o indicador de emprego nos estados, o que pode sinalizar quebra de empresas com menor competividade mediante importações de bens finais mais baratos, ou mudanças tecnológicas poupadoras de mão de obra, sobretudo pouco qualificada. Por outro lado, a abertura comercial favoreceu os indicadores de produção e exportações. Isso sugere que as importações de insumos e equipamentos podem ter beneficiado a modernização do parque produtivo e a redução de custos de produção, ampliando a competitividade industrial. Por fim, a taxa de juros exerceu efeitos negativos em todos os indicadores que apresentaram significância estatística, dificultando os investimentos para ampliação de capacidade produtiva.

Em linhas gerais, algumas das evidências obtidas são sugestivas de desindustrialização, com maior robustez no caso de São Paulo. Todavia, cabe ressaltar as limitações dos modelos estimados. Primeiro, o indicador de produção física, em função dos argumentos apontados por Oreiro e Feijó (2010), não é o mais adequado para tratar a desindustrialização, mas a proxy foi utilizada devido a indisponibilidade de dados mensais sobre VA da indústria de transformação em níveis estaduais. Além disso, tanto a produção como as exportações podem sofrer efeitos distintos das variáveis explicativas analisadas em função da intensidade tecnológica das atividades. Ainda, o indicador de emprego pode ser influenciado pelas variações de produtividade da força de trabalho. 
Todavia, fica o alerta de que, tendo em vista que a indústria é considerada pelos trabalhos desenvolvimentistas um setor primordial para o processo de crescimento e desenvolvimento das economias, os resultados obtidos remetem à necessidade de se pensar de políticas de revitalização da indústria brasileira, com ênfase na configuração de políticas macroeconômicas e industriais que a priorize, ao mesmo tempo em que promova a competividade pelo incentivo à inovação, à qualificação da força de trabalho e inserção no mercado externo.

\section{Referências}

ALMEIDA, T. R. C.; SOUZA, C. C. A. Evolução da estrutura industrial de Minas Gerais no período 1960-2010: uma análise frente aos demais estados da federação. Anais do XVI Seminário sobre a Economia Mineira em Diamantina, Diamantina, 2014.

AMBROZIO, A. M. Aumento do emprego contrasta com desindustrialização em SP e RJ. BNDES Visão do Desenvolvimento, $n^{\circ}$. 5, set., 2007.

BOTELHO, M. R. A.; SOUSA, G. F.; AVELLAR, A. P. M. A incidência desigual do processo de desindustrialização nos estados brasileiros. Anais do XVI Seminário sobre a Economia Mineira de Diamantina, Diamantina, 2014.

BCB. BANCO CENTRAL DO BRASIL. Economia e Finanças. Séries Temporais. Disponível em: http://www.bcb.gov.br/pt-br/\#!/n/SERIESTEMPORAIS. Acesso em: Jan. 2018.

BRESSER-PEREIRA, L. C. Doença holandesa e sua neutralização: uma abordagem ricardiana. Revista de Economia Política, 28 (1), São Paulo. 2007.

CAÇADOR, S. B.; GRASSI, R. A. A evolução recente da economia do Espírito Santo: um estado desenvolvido e periférico? Anais do XXXVII Encontro Nacional de Economia. Foz do Iguaçu, Dezembro, 2009.

CAÇADOR, S. B. A Economia do Espírito Santo está sofrendo um processo de desindustrialização? Redes (St. Cruz Sul, Online), v. 20, nº. 3, Suplemento, p. 341-362, set./dez., 2015.

CANO, W. A desindustrialização no Brasil. Economia e Sociedade, v. 21, número especial, p. 831851, Campinas. 2012.

CARVALHO, L.; KUPFER, D. A transição estrutural da indústria brasileira: da diversificação para a especialização. Anais do XXXV Encontro Nacional de Economia da ANPEC, Recife. 2007.

COSTA, D. O. N.; FUNARI, A. P.; MATTOS, L. O. Evidências da Desindustrialização no Brasil e no Estado de São Paulo entre 1989 e 2010. Anais do VI Seminário Internacional de Desenvolvimento Regional. Santa Cruz do Sul, Rio Grande do Sul, setembro, 2013.

CRUZ, J. L. V. A retomada do crescimento brasileiro e a reestruturação do espaço regional no Norte do Estado do Rio de Janeiro. Vértices, Campos dos Goytacazes/ RJ, v.14, n. Especial 1, p. 31-61, 2012.

CRUZ, B. O.; SANTOS, I. R. S. Dinâmica do emprego industrial no Brasil entre 1990 e 2009: uma visão regional da desindustrialização. Texto para discussão, n. 1673, Secretária de Assuntos Estratégicos da Presidência da República, IPEA, Rio de Janeiro. 2011. 
ENGLE, R. F.; GRANGER, C. W. J. Co-integration and error correction: representation, estimation, and testing. Econometrica. p. 251-276, 1987.

FERreirA, J. S. W. São Paulo: o Mito da Cidade-Global. 2003. 336f. Tese (Doutorado). Faculdade de Arquitetura e Urbanismo, Universidade de São Paulo, São Paulo, 2003.

IBGE. INSTITUTO BRASILEIRO DE GEOGRAFIA E ESTATÍSTICA. Pesquisa Industrial Anual (PIA) - Empresa. Disponível em: https://sidra.ibge.gov.br/pesquisa/piaempresa/tabelas/brasil/2015. Acesso em: Jan. 2018.

IBGE. INSTITUTO BRASILEIRO DE GEOGRAFIA E ESTATÍSTICA. Pesquisa Industrial Mensal - Produção Física Regional (PIM-PF/RG). Disponível em: https://sidra.ibge.gov.br/home/pimpfrg/brasil. Acesso em: Jan. 2018.

IMF. INTERNATIONAL MONETARY FUND. Data and Statistics. IMF Primary Commodity Prices. Disponível em: http://www.imf.org/external/np/res/commod/index.asp. Acesso em: Jan. 2018.

IPEADATA. INSTITUTO DE PESQUISA EM ECONOMIA APLICADA. Dados macroeconômicos. Disponivel em: http://www.ipeadata.gov.br/Default.aspx. Acesso em: Jan. 2018.

JOHANSEN, S. Estimation and Hypothesis Testing of Cointegration Vectors in Gaussian Vector Autoregressive Models. Econometrica, vol. 59, pp. 1551-1580, 1991.

MANHÃES, V. T.; ROSENDO, R. C. Evolução da Densidade Industrial nos Estados do Sudeste Brasileiro (2000/2010): Vivenciamos um Fenômeno de Desindustrialização? Revista de Desenvolvimento Econômico, v. 3, n. 35, p. 924-953, dezembro, 2016.

MDIC. MINISTÉRIO DO DESENVOLVIMENTO, INDÚSTRIA E COMÉRCIO EXTERIOR. Estatísticas do Comércio Exterior. Disponível em: http://www.mdic.gov.br//sitio/interna/interna.php?area=5\&menu=1076. Acesso em: Jan. 2018.

MONTEIRO, F. D. S. C.; LIMA, J. P. R. Desindustrialização regional no Brasil. Nova Economia, v.27, n.2, p.247-293, 2017.

MTE-CAGED. Cadastro Geral de Empregados e Desempregados. Evolução de Emprego do CAGED - EEC. Ministério do Trabalho. Disponível em: http://pdet.mte.gov.br/evolucao-doemprego-do-caged. Acesso em: Jan. 2018.

MTE-RAIS. Relação Anual de Informações Sociais. Dados estatísticos. Ministério do Trabalho. Disponível em: http://pdet.mte.gov.br/acesso-online-as-bases-de-dados. Acesso em: Jan. 2018.

OREIRO, J. L.; FEIJÓ, C. A. Desindustrialização: Conceituação, Causas, Efeitos e o Caso Brasileiro. Revista de Economia Política, v. 30, nº. 2, Abr-Jun, 2010.

PALMA, J. G. Quatro fontes de desindustrialização e um novo conceito de doença holandesa. Federação das Indústrias do Estado de São Paulo. São Paulo. 2005. 
PEREIRA, W. M.; CARIO, S. A. F. Desindustrialização e mudança estrutural na Região Sudeste: um estudo comparado. Anais do $1^{\circ}$ Encontro da Nacional de Economia Industrial e Inovação, vol. $3, n^{\circ} 4$, dezembro, 2016.

PESARAN, M. H.; SHIN, Y. An Autoregressive Distributed-Lag Modelling Approach to Cointegration Analysis. In: Econometrics and Economic Theory in the 20th Century: The Ragnar Frisch Centennial Symposium. Cambridge: Cambridge University Press, 1999.

PESARAN, M. H.; SHIN, Y.; SMITH, R. J. Bounds Testing Approaches to the Analysis of Level Relationships. Journal of Applied Econometrics, vol. 16, n. 3, pp. 289-326, 2001.

PHILLIPS, P. C. B.; HANSEN, B. E. Statistical Inference in Instrumental Variables Regression with I(1) Processes. The Review of Economic Studies, vol. 57, n. 1, pp. 99-125, 1999.

REZENDE, F. A. E.; SANTOS, F. Desindustrialização, rearranjo industrial e desemprego no Brasil. O caso do ABC paulista. Revista Eletrônica, ano 1, n. 1, p. 31-34. 2007.

ROSENDO, R. C.; BRITTO, J. Evolução da densidade industrial do estado do Rio de Janeiro: análise comparativa com os estados de sudeste brasileiro-2000/2005. Anais do XXXIX Encontro Nacional de Economia, ANPEC, Foz do Iguaçu. 2011.

ROWTHORN, R.; WELLS, J. R. De-Industrialization and Foreign Trade. Cambridge, Cambridge University Press. 1987.

ROWTHORN, R.; RAMASWANY, R. Growth, Trade and Deindustrialization. Working Paper, International Monetary Fund, Research Department. 1999.

SOBRAL, B. L. B. A falácia da "inflexão econômica positiva": algumas características da desindustrialização fluminense e do "vazio produtivo" em sua periferia metropolitana. Cadernos do Desenvolvimento Fluminense, n. 1, Rio de Janeiro. 2013.

SONAGLIO, C. M. O comércio de manufaturados e o desenvolvimento econômico: Por que se preocupar com a trajetória brasileira? Revista Estudos do CEPE, Santa Cruz do Sul, n34, p.122138, jul./dez. 2011.

TREGENNA, F. Characterizing deindustrialization: an analysis of changes in manufacturing employment and output internationally. Cambridge Journal of Economics, v. 33, n. 3, Cambridge. 2009.

VERÍSSIMO, M. P.; ARAÚJO, S. C. Perfil industrial de Minas Gerais e a hipótese de desindustrialização estadual. Rev. Bras. Inov., Campinas (SP), 15 (1), p. 113-138, janeiro/junho, 2016.

VILLASCHI FILHO, A.; LEAL, E. A. S. Desindustrialização e doença holandesa: há evidências para a economia brasileira e capixaba? Seminário XX GPIDECA. Departamento de Economia. Universidade Federal do Espírito Santo. 25/04/2012. 